\title{
IHA Fotogrametrisine Genel Bakış: Geleneksel Topoğrafik Harita Yapımı Tekniği ile Maliyet Karşılaştırması
}

\section{Overview of UAV Photogrammetry: Cost Comparison with Traditional Topographic Mapping Technique}

\begin{abstract}
Ali Ulvi ${ }^{*}$
Geliş / Received: 23/02/2021

Revize / Revised: 16/04/2021

Kabul / Accepted: 16/04/2021

ÖZ

Teknolojinin gelişmesine paralel olarak fotogrametri alanında da hızlı gelişmeler olmakta, gittikçe kısalan zaman dilimleri içinde yeni metotlar gelişmektedir. $\mathrm{Bu}$ gelişmeler resim çekim teknikleri ve resimlerin değerlendirme teknikleriyle kendini göstermiştir. Son zamanlarda İnsansız hava araçları (İHA) fotogrametrik değerlendirme sürecinde kendine yer bulmuştur. Buna bağlı olarak da İHA fotogrametrisi literatürde adını sıkça duyurmaya başlamıştır. Bu çalışmada İHA fotogrametrisinin çalışma mantığı, doğruluk analizi ve maliyet analizi üzerinde durulmuştur. Geleneksel yöntemler ile maliyet açısından karşılaştırılmıştır. Gerek zaman ve maliyet tasarrufu açısından, gerekse doğruluk ve görsellik açısından İHA fotogrametrisinin mühendislik projelerinde etkin olarak kullanılabileceği görülmüştür.
\end{abstract}

Anahtar Kelimeler- IHA Fotogrametrisi, SfM, Maliyet Analizi

\begin{abstract}
In parallel with the development of technology, rapid developments are taking place in the field of photogrammetry, and new methods are developed in shorter time frames. These developments showed themselves with the taking picture technique and the evaluation techniques of the pictures. Recently, unmanned aerial vehicles (UAV) have found a place in the photogrammetric evaluation process. Accordingly, UAV photogrammetry has begun to make a name for itself in the literature. In this study, the logic of UAV photogrammetry, accuracy analysis and cost analysis are emphasized. It was compared with traditional methods in terms of cost. It was that UAV photogrammetry can be used effectively in engineering projects in terms of time and cost savings, accuracy, and visuality.
\end{abstract}

Keywords- UAV Photogrammetry, SfM, Cost Analysis

1*Sorumlu yazar iletişim: aliulvi@mersin.edu.tr (https://orcid.org/0000-0003-3005-8011)

Uzaktan Algilama ve Coğrafi Bilgi Sistemleri Anabilim Dali, Mersin Üniversitesi, Fen Bilimleri Enstitüsü, Mersin, Türkiye 


\section{GİRIŞ}

Topografik harita arazi üzerindeki doğal ve yapay detayların belirli ölçeklerde kıymetlendirildiği, eş yükseklik eğrilerinin çizildiği, bu bilgilerin belirli işaretlerle kullanıcıya sunulduğu bir üründür. Bu ürün yersel tekniklerle, teknolojinin gelişmesiyle birlikte hava fotoğraflarından, uydu görüntülerinden ve son yıllarda İHA kullanılarak üretilmektedirler. İHA lar fotogrametrik tekniklerle üretilecek olan haritalar için gerekli olan hava fotoğraflarının elde edilebilmesi için bir platform olarak kullanılmaktadır.

Bilindiği üzere fotogrametrinin ilk uygulamaları yersel fotogrametri alanında yapılmıştır. Fotogrametrinin ilk uygulamaları yersel fotogrametri ile başlamış olsa da zaman içerisinde harita yapımında geniş olanaklar sağlaması nedeni ile yerini hava fotogrametrisi almıştır. Birçok alanda olduğu gibi fotogrametri alanında da hızlı gelişmeler olmakta, gittikçe kısalan zaman dilimleri içinde yeni metotlar gelişmektedir. Özellikle son zamanlarda fotogrametri alanında da, dijital fotogrametri uygulamaları ile çok hızlı değişiklikler yaşanmaktadır. Dijital fotogrametri sayesinde, gerek resim çekiminde, gerekse bu resimlerin değerlendirilmesinde büyük kolaylıklar sağlanmıştır. Klasik hava fotogrametrisinde kullanılan ekipmanlar (özellikle kullanılan hava kameraları) açısından bakıldığında ürünlerin elde edilmesine kadar geçen süreçte maliyet çok fazladır. Ayrıca istenilen zamanda uçuş yapılamaması ve uçuş iznine tabi olmasıyla zamansal açıdan dezavantaj sağlamaktadır.

Son zamanlarda, metrik olmayan dijital kameraların, yersel fotogrametri amaçlı değerlendirme çalışmalarında kullanımı oldukça yaygınlaşmıştır. $\mathrm{Bu}$ tip kameraların yersel fotogrametri amaçlı metrik kameralara göre fiyatlarının çok daha düşük olması kullanıcıların ilgisini çekmekte ve birçok projede yaygın olarak kullanılmaktadır. Fotogrametrik amaçlar için üretilmemelerine rağmen, film kameralarına oranla çok yoğun bir uygulama avantajına sahip olan dijital kameralar fotogrametri de güçlü ve etkin dijital veri elde etme aracı olarak kullanılmaktadırlar [1]. Teknolojideki gelişmeler dijital kameraları taşıyan taşıyıcı plarformlarda da kendini göstermiş̧ir. Buna bağlı olarak dronların ve sabit kanatlı hava araçların kullanımı mühendislik projelerinde yaygınlaşmaya başlamıştır. Süreç içerisinde bu taşıyıcı platformların ismi İHA olarak anılmaya başlanmıştır. İHA ların taşıyıcı platform olarak kullanılmasıyla birlikte uçuş irtifasını da göz önüne alarak İHA fotogrametrisi yersel fotogrametri ve hava fotogrametrisi arasında literatürde kendine yer bulmuştur.

Bu çalışma Selçuk Üniversitesi Alaaddin Keykubat kampüsünde 512 Ha lık alan pilot bölge olarak seçilmiştir. Bu bölgede fotogrametrik çalışmaların sonuç ürünleri ele alınmış, maliyet analizi yapılmış ve aynı alanın geleneksel yöntemlerle yapılması durumundaki maliyetler araştııılmıştır. İHA ile yapılan fotogrametrik çalışmaların maliyet analizlerinde iki farklı İHA sistemi incelenmiş̧ir. Bu sistemler sabit kanatlı ve döner kanatlı sistemlerdir.

\section{II. İHA FOTOGRAMETRISI}

İHA fotogrametrisi, genel olarak içerisinde herhangi bir insan taşımadan, otonom veya manuel olarak kontrol edilebilen bir hava aracına entegre edilen kamera ile çekilmiş fotoğraflar kullanılarak yapılan fotogrametrik sürecin genel tanımıdır. Bu bağlamda IHHA fotogrametrisi özellikle yeni gelişen görüntü işleme teklikleri ile mimari, arkeolojik ve tarihi eserlerin 3B modelleme çalışmalarının gözdesi haline gelmiştir.

İHA'lar ile geleneksel veri toplama yöntemlerine göre daha fazla esneklik sağlanırken çalışma alanında daha az zaman harcanmaktadır ve ayrıca maliyet açısından önemli avantajlar sağlanmaktadır [2]. Ayrıca yeni tip İHA'lara entegre edilen Global Position System (GPS) sayesinde çekilen resimlerin enlem, boylam ve yükseklik bilgilerinin olması bu sistemin avantajları arasında yer almaktadır. Ek olarak hem GPS modülünün olması hem de bu İHA'lar ile otomatik resim çekebilmesi distorsiyonun (öteleme, dönüklük ve kayıklık) önemli derecede azalmasına katkı sağlamaktadır. Dahası, İHA'ların alçak irtifadan uçuş kabiliyeti ve gelişmiş teknik görüntüleme sistemleri ile birlikte elde ettikleri veriler, uydu görüntülerinden ve insanlı uçaklardan elde edilen verilere kıyasla önemli ölçüde daha yüksek çözünürlüğe sahip ve çok daha detaylı bilgiler içermektedir.

İHA'lar ilk olarak askeri uygulamalarda kullanılmaya başlanmıştır. Daha sonra sivil kullanıma izin verilmesi ile birlikte hassas tarım [3] ve ormancılık çalışmalarında [4] kullanılmaya başlanmış ardından yangın izleme $[5,6]$ kültürel miras ve arkeoloji $[7,8]$ trafik izleme $[9,10]$ çevresel araştırma $[11,12]$ ve üç boyutlu (3B) rekonstrüksiyon [13-15] gibi alanlarında teknolojinin gelişmesi ile birlikte birçok disiplin tarafından farklı amaç doğrultusunda kullanılmaya devam etmiştir.

İHA fotogrametrisinin ile bütünleșik çalıșan açık kaynak kodlu ve ticari birçok yazılım bulunmaktadır. Bu yazılımların pek çoğu Structure from motion (SfM) özel algoritmalara dayanmaktadır. SfM, iki boyutlu (2B) görüntü dizilerinden 3B yapıları tahmin etmek için kullanılan bir fotogrametrik görüntüleme tekniğidir. SfM 


\begin{tabular}{|c|c|c|}
\hline & $\begin{array}{l}\text { BŞEÜ Fen Bilimleri Dergisi } \\
8(1), 458-471,2021\end{array}$ & $\begin{array}{r}\text { BSEU Journal of Science } \\
\text { https://doi.org/10.35193/bseufbd } 885579\end{array}$ \\
\hline 0 & & 2458-7575 (https://dergipark.org.tr/tr/pub/bseufbd) \\
\hline
\end{tabular}

yönteminde, üst üste binen çerçevelerin bir dizisinden 3B yapılar oluşturulur (Şekil 1). Kısa bir süre içinde SfM; olağanüstü hızlı, düşük maliyetli ve kolay 3D ölçümler sağlayan yerbilimi araştırmaları üzerinde dönüştürücü bir etkiye sahip olmuştur [16]. Bunun sebebi SfM tekniği, belirli çalışma yöntemlerine uyulduğu takdirde yersel ve havadan farklı çekim platformlarından alınan fotoğrafların entegre edilmesi olanağını da sunmaktadır. Geleneksel stereoskopik fotogrametri ile SfM yöntemi arasındaki temel fark, 3B uzayda bir noktanın kesin konumunun elde edilmesi için gerekli hesaplamaların tam otomatik yapılması ve kameraların hassas konumlandırılmasına gerek olmamasidır.

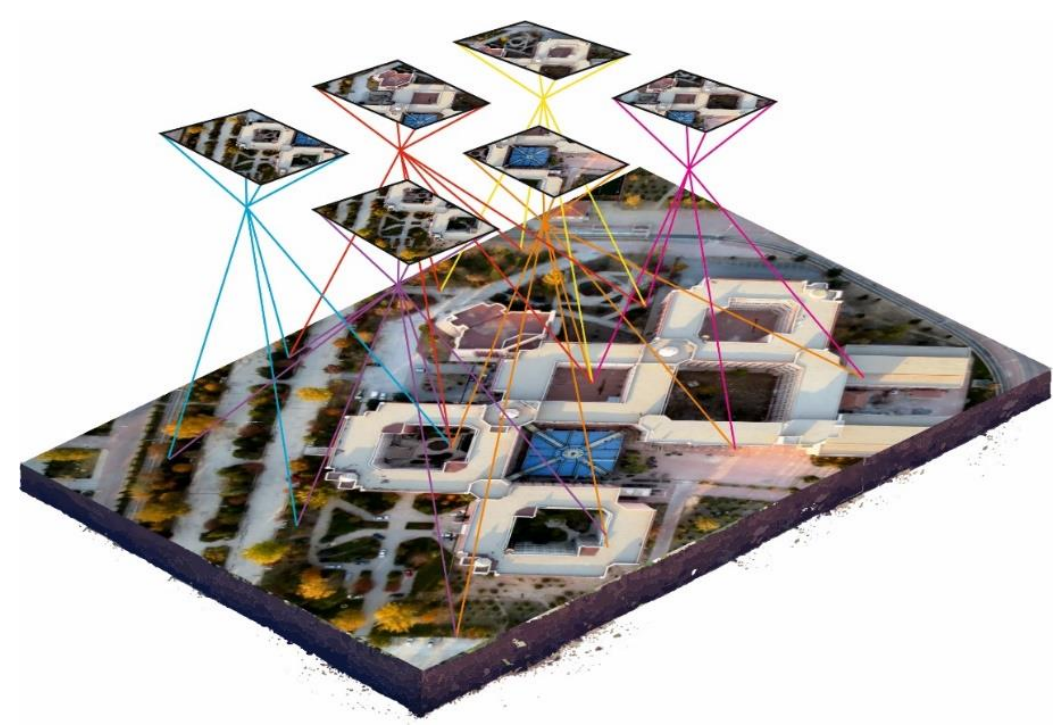

Şekil 1. SfM mantı̆̆ı ile arazinin fotoğraflanması işlemi

İHA fotogrametrisi genel olarak arazi çalışması ve ofis çalışması olarak iki aşamadan oluşmaktadır. Bu çalışmanın genel iş akış şeması Şekil 2' de gösterilmektedir.

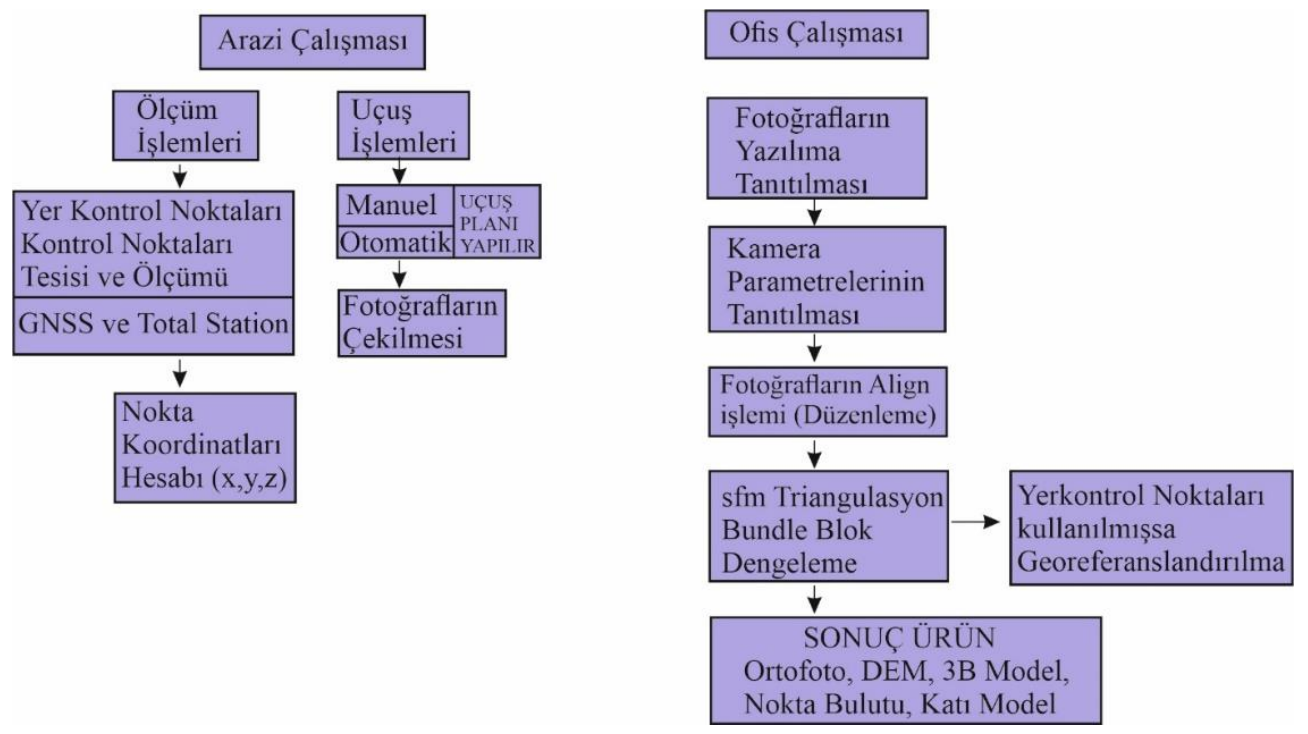

Şekil 2. İHA fotogrametrisi iş akış şeması 


\begin{tabular}{|c|c|c|}
\hline & $\begin{array}{l}\text { BŞEÜ Fen Bilimleri Dergisi } \\
8(1), 458-471,2021\end{array}$ & $\begin{array}{r}\text { BSEU Journal of Science } \\
\text { https://doi.org/10.35193/bseufbd } 885579\end{array}$ \\
\hline 0 & & 2458-7575 (https://dergipark.org.tr/tr/pub/bseufbd) \\
\hline
\end{tabular}

\section{III. ÇALIŞMA ALANI}

Çalışma alanı Konya ili Selçuk Üniversitesi Alaaddin Keykubat kampüsünde gerçekleştirilmiştir (Şekil 3). Çalışma alanı 512 ha oluşmaktadır.

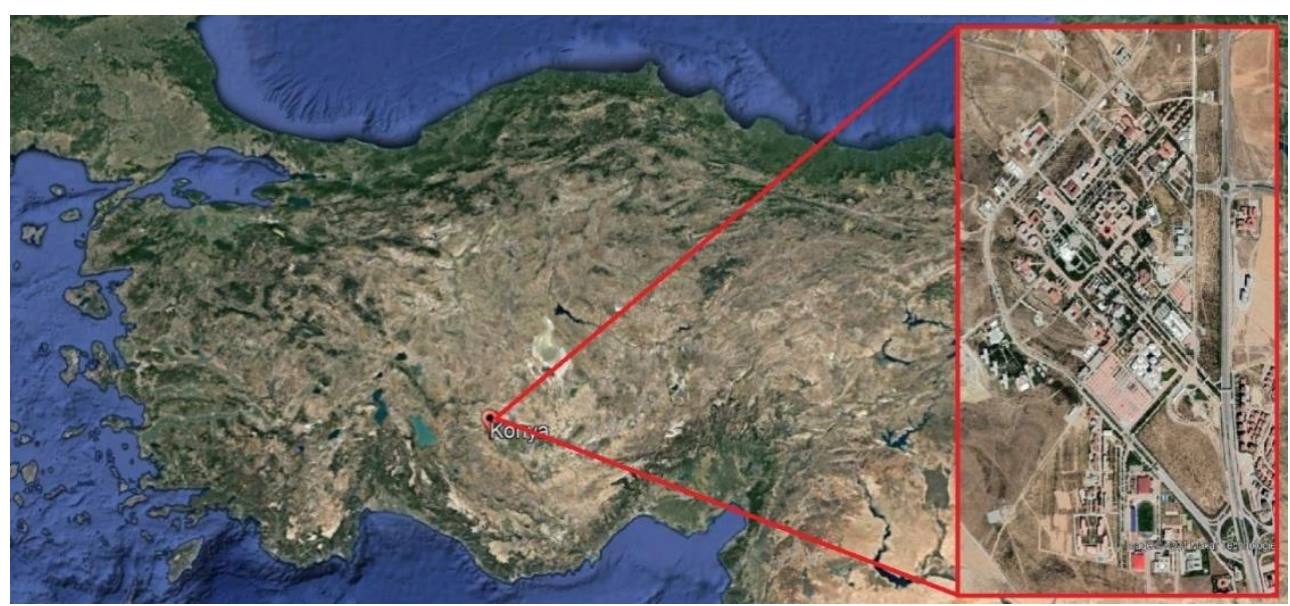

Şekil 3. Selçuk üniversitesi kampüsü çalışma alanı olarak belirlenmiş̧ir.

\section{METODOLOJI}

\section{A. Verilerin Toplanmast}

Çalışma alanının ortofoto haritasının üretilebilmesi için öncelikle alana 24 adet Yer kontrol noktası (YKN) , 30 adet test noktası tesis edilmiştir. Tesis edilen noktaların kalıcı olabilmesi için karayolları kurumunun kullandığı yol çizgi boyası kullanılmıştır (Şekil 4). Tesis edilen YKN lerin koordinatlandııılması işlemi ise Topcon GR5 Global Positioning System (GPS) cihazı ile ITRF96 datum sisteminde yapılmışır (Şekil 4).

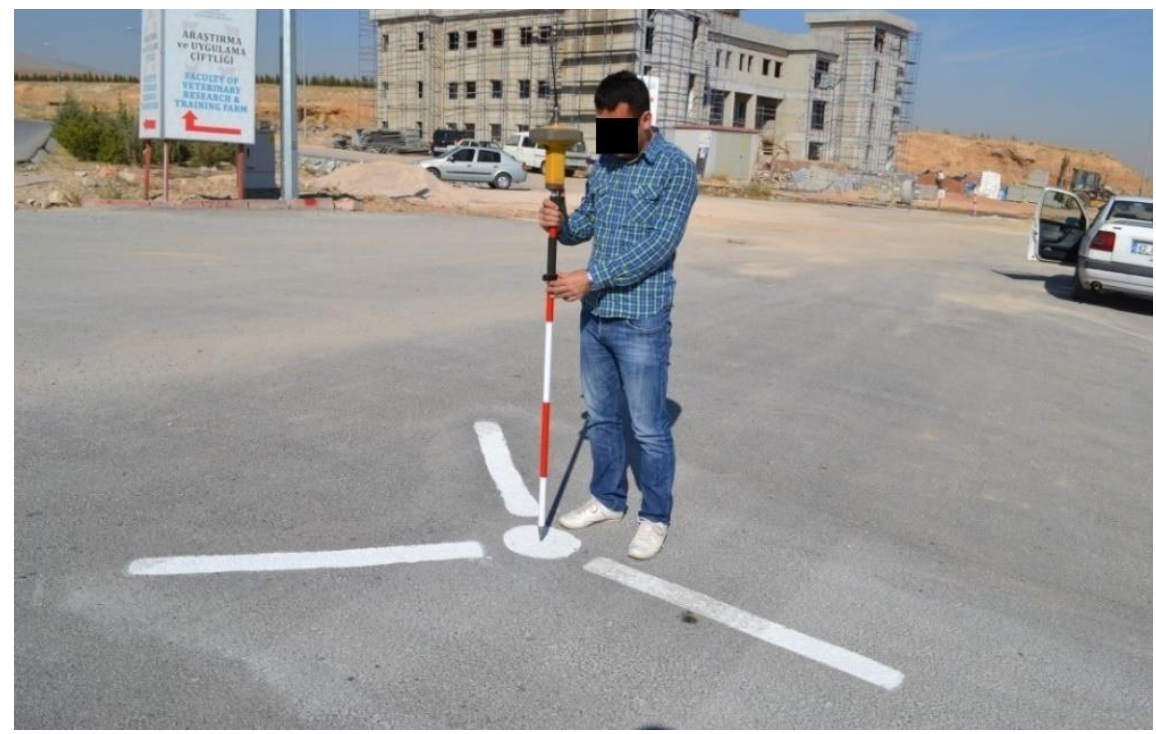

Şekil 4. YKN'lerin koordinatlandırılması işlemi

Çalışma alanının fotoğrafları 2 farklı cihaz tarafından çekilmiştir. Bu cihazlar ebee (Şekil 5a) ve microcopter (Şekil 5b) hava araçlarıdır. Ebee cihazı sabit kanatlı, microcopter ise döner kanatlı insansız hava araçlarıdır. Ebee cihazı üzerinde Canon IXUS 125, microcopter üzerinde ise Canon A810 dijital kamerası bulunmaktadır. Uçuş için yer örnekleme aralığ $5.76 \mathrm{~cm}$ olarak belirlenmiştir. Bu kameraların teknik özellikleri Tablo 1 de gösterilmektedir. 


\begin{tabular}{|c|c|c|}
\hline & $\begin{array}{l}\text { BŞEÜ Fen Bilimleri Dergisi } \\
8(1), 458-471,2021\end{array}$ & $\begin{array}{r}\text { BSEU Journal of Science } \\
\text { https://doi.org/10.35193/bseufbd.885579 }\end{array}$ \\
\hline $\begin{array}{l}\text { BïLECIK SEYH EDEBALI| } \\
\text { UNIVERSITES I }\end{array}$ & & 2458-7575 (https://dergipark.org.tr/tr/pub/bseufbd) \\
\hline
\end{tabular}

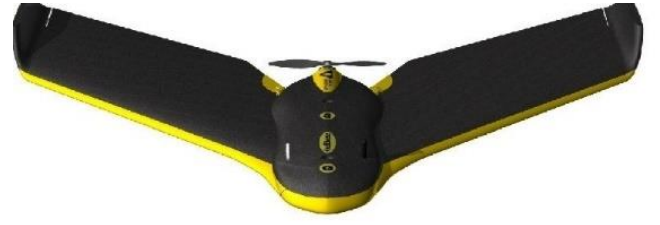

( a )

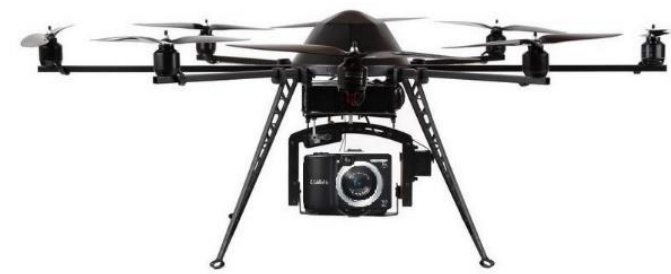

( b )

Şekil 5. (a) Ebee İHA, (b) microcopter İHA

Tablo 1. İHA kamera teknik özellikleri

\begin{tabular}{ccccc}
\hline Uav & Number of photos & Uav camera & Resolution (pixel) & Pixel pitch \\
\hline Microcopter & 810 & Canon A810 & $4608 \times 3456$ & $1.34 \mu \mathrm{m}$ \\
Ebee & 725 & Canon IXUS 125 & $4608 \times 3456$ & $1.34 \mu \mathrm{m}$ \\
\hline
\end{tabular}

Fotoğrafların dengelenmesi ve değerlendirilmesi işlemi Leica Photogrammetric Suit (LPS) tarafından yapılmıştır. Çalışmanın sonucunda çalışma alanına ait ortofoto harita (Şekil 6a) ve digital elevation model (DEM) (Şekil 6b) haritası üretilmiştir.

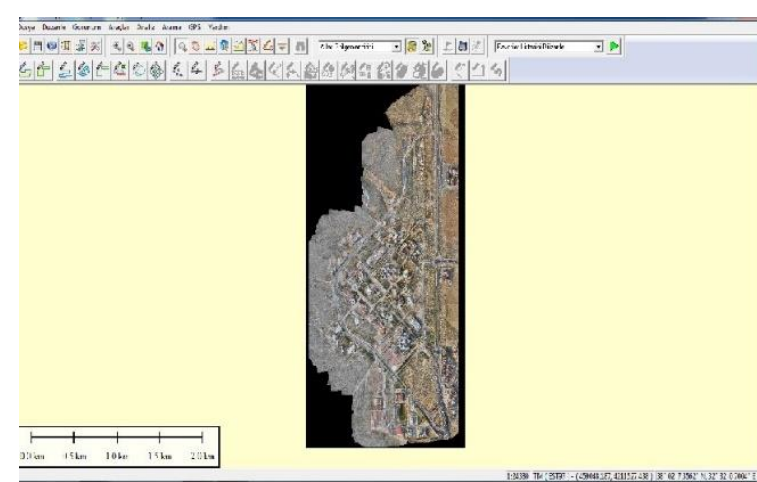

( a )

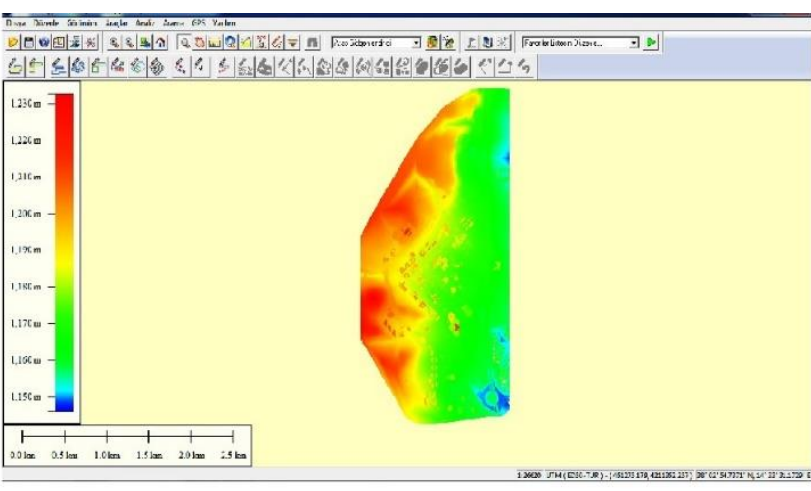

( b )

Şekil 6. (a) Çalışma alanına ait ortofoto harita, (b) Çalışma alanına ait DEM haritası

\section{B. Doğruluk Değerlendirmesi}

Çalışma alanına 30 adet test noktaları homojen olarak tesis edilmiştir. Bu noktaların koordinatları GNSS cihazı ile ölçülmüştür. Bu koordinatlar referans koordinatlar olarak kabul edilmiştir. Doğruluk analizinde karesel ortalama hata denklemleri kullanılmıştır. Fotogrametrik projenin doğruluğu geo referanslamada kullanılmayan kontrol noktaları kullanılarak hesaplanmıştır[17,18]. Bu kapsamda, kontrol noktaları orto görüntülerde tanımlanmış ve koordinatları incelenen GNSS koordinatlarıyla karşılaştırılarak aşağıda verilen denklemlerde tanımlandığı gibi RMSE x, RMSE y yatay doğruluk ölçüleri elde edilmiştir:

$$
\begin{aligned}
& R M S E_{x}=\frac{\sum_{i=1}^{n}\left(X_{O \mathrm{i}}-X_{G N S S \mathrm{i}}\right)^{2}}{n} \\
& R M S E_{y}=\frac{\sum_{i=1}^{n}\left(Y_{O \mathrm{i}}-Y_{G N S S \mathrm{i}}\right)^{2}}{n} \\
& R M S E_{z}=\frac{\sum_{i=1}^{n}\left(z_{O \mathrm{i}}-Z_{G N S S \mathrm{i}}\right)^{2}}{n} \\
& R M S E_{x y z}=\sqrt{\frac{\sum_{i=1}^{n}\left(X_{O \mathrm{i}}-X_{G N S S \mathrm{i}}\right)^{2}+\left(Y_{O \mathrm{i}}-Y_{G N S S \mathrm{i}}\right)^{2}+\left(Z_{O \mathrm{i}}-Z_{G N S S \mathrm{i}}\right)^{2}}{n}}
\end{aligned}
$$


(a) $\mathrm{N}$, her proje için test edilen kontrol nokta sayısıdır.

(b) $X_{O \mathrm{I}}$ and $Y_{O \mathrm{I}}$ sirasıyla ortofotodan ölçülen x ve y koordinatlarıdır.

(c) $X_{G N S S}$ and $Y_{G N S S i}$ kontrol noktalarının GNSS ile ölçülen x ve y koordinatlarıdır.

Ayrıca, yükseklik değerleri orto görüntüdeki CP'nin x ve y koordinatları için gridDSM'den türetilmiş ve GNSS koordinatı ile karşılaştırılmıştır. Sonuç olarak, Denklem (3) 'te tanımlandığı gibi z yönü için bir $R M S E_{z}$ doğruluk ölçüsü üretilmiştir.

(a) $Z_{O \mathrm{i}}$ ortofotoda ölçülen $\mathrm{x}$ ve y koordinatları dikkate alınarak DSM'den türetilen kontrol noktasındaki yüksekliktir.

(b) $Z_{G N S S i}$ kontrol noktasının GNSS ile ölçülen $Z$ koordinatıdır.

Tablo 2. Kesin koordinatlar ve ortofoto koordinatlar

\begin{tabular}{|c|c|c|c|c|c|c|c|c|c|c|c|}
\hline \multicolumn{4}{|c|}{ KESİN KOORDINATLAR } & \multicolumn{4}{|c|}{ ORTOFOTO NOKTALAR (EBEE) } & \multicolumn{4}{|c|}{ ORTOFOTO NOKTALAR (Microcopter) } \\
\hline N.N. & $\mathbf{Y}(\mathbf{m})$ & $\mathbf{X}(\mathbf{m})$ & $\mathbf{Z}(\mathbf{m})$ & N.N. & $\mathbf{Y}(\mathbf{m})$ & $\mathbf{X}(\mathbf{m})$ & $\mathbf{Z}(\mathbf{m})$ & N.N. & $\mathbf{Y}(\mathbf{m})$ & $\mathbf{X}(\mathbf{m})$ & $\mathbf{Z}(\mathbf{m})$ \\
\hline 1 & 457065.005 & 209572.14 & 169.564 & 1 & 457065.082 & 4209572.22 & 1169.54 & 1 & 457064.95 & 4209572.09 & 1169.622 \\
\hline 2 & 457060.601 & 4209573.86 & 1169.646 & 2 & 457060.632 & 4209573.93 & 1169.694 & 2 & 457060.641 & 4209573.8 & 1169.701 \\
\hline 3 & 457056.281 & 4209571.95 & 1169.652 & 3 & 457056.317 & 4209571.99 & 1169.595 & 3 & 457056.337 & 4209571.98 & 1169.583 \\
\hline 4 & 457054.539 & 4209567.54 & 1169.641 & 4 & 457054.561 & 4209567.62 & 1169.593 & 4 & 457054.485 & 4209567.58 & 1169.693 \\
\hline 5 & 457056.491 & 4209563.1 & 1169.672 & 5 & 457056.509 & 4209563.12 & 1169.595 & 5 & 457056.436 & 4209563.07 & 1169.605 \\
\hline 6 & 457060.924 & 4209561.33 & 1169.631 & 6 & 457060.998 & 4209561.36 & 1169.675 & 6 & 457060.859 & 4209561.32 & 1169.655 \\
\hline 7 & 457065.225 & 4209563.24 & 1169.69 & 7 & 457065.303 & 4209563.31 & 1169.728 & 7 & 457065.275 & 4209563.29 & 1169.746 \\
\hline 8 & 457066.974 & 4209567.73 & 1169.794 & 8 & 457067.027 & 4209567.77 & 1169.757 & 8 & 457066.925 & 4209567.68 & 1169.743 \\
\hline 9 & 457074.304 & 4209583.87 & 1169.512 & 9 & 457074.384 & 4209583.79 & 1169.546 & 9 & 457074.374 & 4209583.82 & 1169.445 \\
\hline 10 & 457073.263 & 4209584.94 & 1169.525 & 10 & 457073.316 & 4209584.91 & 1169.592 & 10 & 457073.215 & 4209584.96 & 1169.582 \\
\hline 11 & 457006.003 & 4209973.45 & 1174.02 & 11 & 457005.945 & 4209973.39 & 1173.996 & 11 & 457005.961 & 4209973.49 & 1173.978 \\
\hline 12 & 457014.99 & 4209982.31 & 1173.742 & 12 & 457014.914 & 4209982.33 & 1173.764 & 12 & 457014.928 & 4209982.34 & 1173.771 \\
\hline 13 & 457002.343 & 4210008.29 & 1174.559 & 13 & 457002.256 & 4210008.26 & 1174.488 & 13 & 457002.403 & 4210008.33 & 1174.612 \\
\hline 14 & 456997.061 & 4209992 & 1174.99 & 14 & 456997.017 & 4209992.06 & 1174.918 & 14 & 456997.123 & 4209991.95 & 1174.943 \\
\hline 15 & 457173.555 & 4210559.09 & 1172.677 & 15 & 457173.513 & 4210559.12 & 1172.597 & 15 & 457173.603 & 4210559.12 & 1172.635 \\
\hline 16 & 457173.524 & 4210559.09 & 1172.539 & 16 & 457173.458 & 4210559.01 & 1172.559 & 16 & 457173.56 & 4210559.13 & 1172.565 \\
\hline 17 & 457189.098 & 4210521.43 & 1172.732 & 17 & 457189.1 & 4210521.49 & 1172.765 & 17 & 457189.136 & 4210521.46 & 1172.674 \\
\hline 18 & 457189.064 & 4210521.42 & 1171.858 & 18 & 457188.983 & 4210521.45 & 1171.788 & 18 & 457189.111 & 4210521.45 & 1171.818 \\
\hline 19 & 457108.975 & 4210622.3 & 1174.897 & 19 & 457108.897 & 4210622.31 & 1174.869 & 19 & 457108.897 & 4210622.33 & 1174.846 \\
\hline 20 & 457091.317 & 4210639.66 & 1175.397 & 20 & 457091.396 & 4210639.67 & 1175.319 & 20 & 457091.383 & 4210639.68 & 1175.329 \\
\hline 21 & 457082.98 & 4210659.6 & 1175.852 & 21 & 457082.954 & 4210659.58 & 1175.785 & 21 & 457083.045 & 4210659.56 & 1175.794 \\
\hline 22 & 457069.209 & 4210675.32 & 1176.217 & 22 & 457069.241 & 4210675.25 & 1176.237 & 22 & 457069.261 & 4210675.27 & 1176.259 \\
\hline 23 & 457057.021 & 4210689.29 & 1176.925 & 23 & 457057.1 & 4210689.36 & 1176.881 & 23 & 457056.975 & 4210689.32 & 1176.875 \\
\hline 24 & 457044.067 & 4210771.02 & 1179.344 & 24 & 457044.146 & 4210771 & 1179.414 & 24 & 457044.126 & 4210771.06 & 1179.404 \\
\hline 25 & 457047.645 & 4210774.55 & 1179.292 & 25 & 457047.708 & 4210774.54 & 1179.355 & 25 & 457047.615 & 4210774.5 & 1179.342 \\
\hline 26 & 456994.315 & 4209599.58 & 1171.171 & 26 & 456994.335 & 4209599.65 & 1171.244 & 26 & 456994.362 & 4209599.63 & 1171.125 \\
\hline 27 & 456976.789 & 4209616.72 & 1171.934 & 27 & 456976.757 & 4209616.77 & 1171.92 & 27 & 456976.722 & 4209616.75 & 1171.96 \\
\hline 28 & 456976.876 & 4209622.5 & 1172.017 & 28 & 456976.859 & 4209622.57 & 1172.094 & 28 & 456976.899 & 4209622.56 & 1172.071 \\
\hline 29 & 456793.097 & 4210602.15 & 1181.819 & 29 & 456793.169 & 4210602.15 & 1181.856 & 29 & 456793.03 & 4210602.21 & 1181.857 \\
\hline 200 & 456530.869 & 4210884.75 & 1202.494 & 200 & 456530.914 & 4210884.67 & 1202.464 & 200 & 456530.902 & 4210884.7 & 1202.534 \\
\hline
\end{tabular}




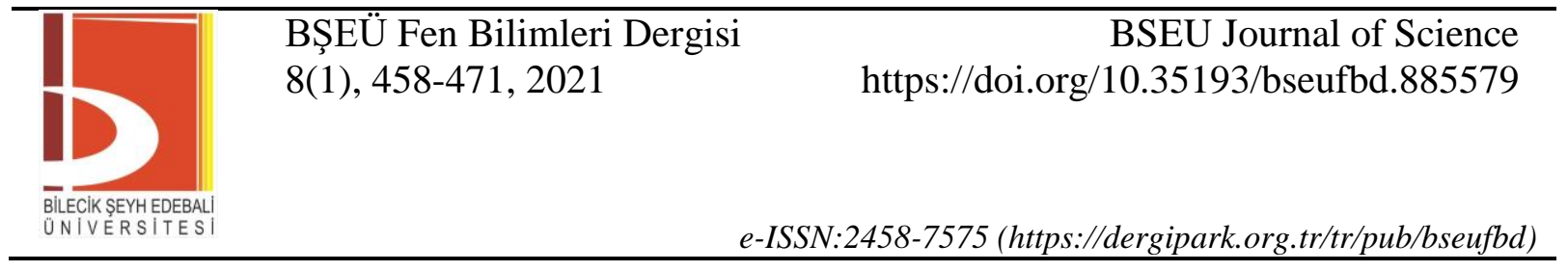

Tablo 3. Fark değerlerinin karesi

\begin{tabular}{cccccccccccccc}
\hline & EBEE & \multicolumn{3}{c}{ OCTOCOPTER } & \multicolumn{3}{c}{ EBEE } & \multicolumn{5}{c}{ OCTOCOPTER } \\
\hline & $\mathbf{V x V x}$ & $\mathbf{V y V y}$ & $\mathbf{V z V z}$ & $\mathbf{V x V x}$ & $\mathbf{V y V y}$ & $\mathbf{V z V z}$ & & $\mathbf{V x V x}$ & $\mathbf{V y V y}$ & $\mathbf{V z V z}$ & $\mathbf{V x V x}$ & $\mathbf{V y V y}$ & $\mathbf{V z V z}$ \\
\hline 1 & 60.1 & 58.5 & 5.8 & 29.7 & 33.1 & 33.6 & 16 & 42.9 & 57 & 4 & 13.3 & 20.7 & 6.8 \\
2 & 9.6 & 51.8 & 23.5 & 16 & 29.2 & 30.8 & 17 & 0.1 & 36 & 10.9 & 14.8 & 13 & 33.6 \\
3 & 13.3 & 15.6 & 33 & 31.9 & 9.9 & 48.3 & 18 & 64.8 & 13.7 & 49 & 22.6 & 12.3 & 16 \\
4 & 5.1 & 58.5 & 23 & 28.6 & 14.8 & 27 & 19 & 60.8 & 0.8 & 8.1 & 60.8 & 7.3 & 26.5 \\
5 & 3.2 & 4.4 & 59.3 & 30.3 & 14.4 & 44.9 & 20 & 62.4 & 1.8 & 60.1 & 43.6 & 5.5 & 45.6 \\
6 & 54.8 & 10.9 & 19.4 & 42.3 & 1.7 & 5.8 & 21 & 6.5 & 4.4 & 44.9 & 42.9 & 16.8 & 33.6 \\
7 & 60.8 & 51.1 & 14.4 & 25 & 24.5 & 31.4 & 22 & 10.6 & 56.3 & 4 & 27.6 & 24 & 17.7 \\
8 & 28.1 & 17.6 & 13.7 & 24 & 17.6 & 26 & 23 & 62.4 & 46.9 & 19.3 & 21.2 & 11.9 & 25 \\
9 & 64 & 53.3 & 11.9 & 49 & 25 & 44.3 & 24 & 62.4 & 2 & 48.3 & 34.8 & 16 & 35.4 \\
10 & 28.6 & 4.8 & 44.9 & 22.6 & 4.8 & 32.5 & 25 & 40.3 & 1 & 39.1 & 8.7 & 27 & 24.5 \\
11 & 33.1 & 33.1 & 5.7 & 17.2 & 17.2 & 17.6 & 26 & 4 & 42.3 & 53.3 & 22.1 & 17.6 & 21.2 \\
12 & 57 & 7.8 & 4.6 & 37.8 & 15.2 & 8.1 & 27 & 10.2 & 24.5 & 1.8 & 44.9 & 12.6 & 7 \\
13 & 75.7 & 6.3 & 50.4 & 36 & 16.8 & 28.1 & 28 & 2.7 & 54 & 59.3 & 5.5 & 29.7 & 29.2 \\
14 & 18.9 & 45.6 & 51.1 & 39.1 & 17.2 & 21.6 & 29 & 51.8 & 0.2 & 13.7 & 44.9 & 31.4 & 14.4 \\
15 & 17.6 & 9 & 64 & 23 & 13 & 17.6 & 200 & 20.2 & 62.4 & 9 & 10.9 & 21.2 & 16 \\
\hline
\end{tabular}

Bu veriler ışığında İHA ile fotogrametrik teknikler kullanılarak üretilen hâlihazır haritanın hassasiyet araştırmasında İHA lara ait $\mathrm{y}, \mathrm{x}$ ve $\mathrm{z}$ koordinatlarında ortalama konum hataları $\pm 9.5 \mathrm{~cm}, \pm 8.5 \mathrm{~cm}$ bulunmuştur (Tablo 4).

Tablo 4. İHA lar ile üretilen ortofoto haritaların karesel ortalama hataları

\begin{tabular}{ccccc}
\hline $\mathbf{m y}$ & $\mathbf{m x}$ & $\mathbf{m z}$ & $\mathbf{m y x z}$ & IHA \\
\hline 5.9 & 5.3 & 5.3 & 9.5 & (Ebee-SabitKanat) \\
5.4 & 4.2 & 5.1 & 8.5 & (Octocopter-DönerKanat) \\
\hline
\end{tabular}

\section{MALIYET ANALIZí}

\section{A. IHA Fotogrametrisi Maliyet Analizi}

İHA ile yapılan fotogrametrik çalışmaların maliyet analizlerinde iki farklı İHA sistemi incelenmiştir. Bu sistemler sabit kanatlı ve döner kanatlı sistemlerdir. Uçuş planlaması ve kıymetlendirme işlemlerinde çalışan teknik personel olarak harita mühendisi düşünülmüştür. HKMO 2020 yılı 2.yarıyılı birim fiyatları baz alınarak bir mühendisinin gündelik ücreti $250 \mathrm{TL}$, saatlik ücreti ise $6.92 \mathrm{TL}$ dir.

İncelenen sistem İHA olan sabit kanatlı uçak sistemidir. Pilot bölgede yapılan uçuşlar sonucunda bölgeye ait harita üretimi gerçekleştirilmiştir. Bu işlem sonucunda tüm maliyetler çıkarılmıştır. Bu çalışmada kullanılan yazılım ve donanımların mevcut olduğu varsayılmıştır. Arazide Yer Kontrol Noktalarının (YKN) ölçülmesi işinde kullanılan GNSS cihazının yaklaşık maliyeti 40000 tl olarak belirlenmiştir. Ölçüm cihazının üç yıl sonra üst modelinin çıkacağı hesap edilmiştir. Bu süre içerisinde yaklaşık yüz elli defa araziye çıkılıp ölçüm yapılacağı hesap edilerek amortisman süresi üç yıl olarak belirlenmiştir. GNSS cihazının arazideki her ölçümü iki saat olarak hesap edilmiştir. GNSS saatlik maliyet $=[$ Satın alma maliyeti/(150x2) $]$

Bu formüle göre GNSS in bir saatlik ölçüm maliyeti=[40000/(150x2)] = 133.33 TL dir.

Kullanılan İHA nın bedeli 380.800 TL dir. İHA nın bir üst modeli yaklaşık üç yıl sonra çıktığı hesap edilmiştir. Bu üç yıl içerisinde yaklaşık yüz uçuş yapılacağı hesap edilerek yüz uçuş sonucunda amortisman gideri uçağın satın alma maliyetidir. İHA' nın saatlik uçuş maliyetini ise her uçuşu iki saat olarak değerlendirdikten sonra aşağıdaki formül bulunmuştur. İHA Saatlik maliyet $=$ [Satın alma maliyeti/(100x2)] 
Bu formüle göre İHA' nın bir saatlik uçuş maliyeti=[380.800/(100x2)]= 1904 TL dir. Pilot bölgenin fotogrametrik olarak alımının yapılması için uçuş planlaması yapılmıştır. Bu planlama bir saat sürmüş planlama sonucunda uçulacak kolon sayısı, uçuş yüksekliği ve fotoğrafların enine ve boyuna bindirme oranları hesap edilmiştir. Bu çalışmada otuz adet Yer Kontrol Noktası (YKN) tesis edilmiştir. YKN tesisinde Karayolları Genel Müdürlüğünün kullandığı güneş 1şınları ve kış şartlarına dayanıklılığından dolayı yol çizgi boyası kullanılmıştır. Burada harcanan boya miktarı $5 \mathrm{~kg}$ boyanın kg maliyeti ise $120 \mathrm{TL}$ dir. Bu boyanın 1 adet YKN maliyeti ise; $(120 \times 5) / 30=20 \mathrm{TL}$ dir.

Bölgenin fotoğraflanması çalışması 725 adet fotoğraf çekimi ile tamamlanmıştır. Bu fotoğraflar iki adet uçuş yapılarak iki adet lipo pil harcanarak elde edilmiştir. Bir pilin satın alma maliyeti $2100 \mathrm{TL}$ dir. Bir fotoğrafın çekim maliyeti ise: $[((2100 \times 2) / 100) / 725]=0.05 \mathrm{TL}$ dir. Fotoğrafların değerlendirildiği yazılım maliyeti ise 4045 \$ dır. 22.10.2020 Günü Saat 21:30'da Belirlenen Gösterge Niteliğindeki Türkiye Cumhuriyet Merkez Bankas1 doların kur fiyatı ise 7,94 TL olarak alınmıştır. Yazılımın yaklaşık fiyatı 4045 x 7,94 = 32117 TL dir. Yazılımın üst versiyonu ortalama üç yılda çıktığı öngörülerek amortismanı hesap edilmiştir. Dolayısıyla bu üç yıl süre içerisinde yüz uçuşluk değerlendirme işlemi yapılacağı hesap edilerek yazılımın bir saatlik değerlendirme maliyeti; $[32117 /(100 \times 24)]=13.38 \mathrm{TL}$ dir.

Bu hesaplamaların sonucunda Sabit kanatı İHA fotogrametrisinin yaklaşık maliyet hesabı Tablo 5 de bulunmuştur. 


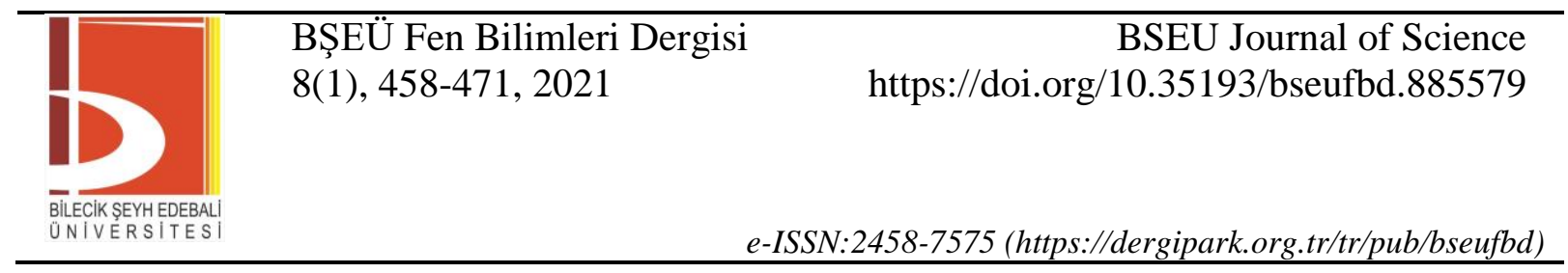

Tablo 5. Sabit kanatlı hava fotogrametrisi yaklaşık maliyet hesabı

\begin{tabular}{|c|c|c|c|c|c|c|c|c|c|c|}
\hline & İşlem & $\begin{array}{l}\text { Süre } \\
\text { (Saat) }\end{array}$ & $\begin{array}{l}\text { Personel } \\
\text { Sayısı }\end{array}$ & $\begin{array}{c}\text { Personel } \\
\text { Ücreti } \\
\text { (250 Tl/Gün) }\end{array}$ & $\begin{array}{c}\text { Uçuş } \\
\text { UUcreti } \\
\text { (Tl/Saat) }\end{array}$ & $\begin{array}{c}\text { Yazllim } \\
\text { Ücreti } \\
\text { (13.38tl/Saat) }\end{array}$ & $\begin{array}{c}\text { Donanım } \\
\text { Ücreti } \\
\text { (Tl/Saat) }\end{array}$ & $\begin{array}{c}\text { Hizmet } \\
\text { Miktarı } \\
\text { (Adet) }\end{array}$ & $\begin{array}{l}\text { Hizmet } \\
\text { Ücreti } \\
\text { (T1/Adet) }\end{array}$ & $\Sigma(\mathrm{Tl})$ \\
\hline \multirow{3}{*}{1} & Uçuş Hizmet Bedeli & & & & & & & & & \\
\hline & İntikal & & & & & & & & & \\
\hline & Uçuş & 2 & 1 & 250 & 1904 & & & & & 4058 \\
\hline \multirow{2}{*}{2} & Uçuş öncesi ve sonrası gerçekleştirilen hizmetle & & & & & & & & & \\
\hline & Uçuş Planlaması & 1 & 1 & & & & & & & \\
\hline \multirow{4}{*}{3} & $\begin{array}{l}\text { Yer Kontrol Noktası inşaası ve ölçüm hizmeti } \\
\text { (Arazi) (GNSS cihazı) }\end{array}$ & 2 & & & & & 133.33 & & & 266.66 \\
\hline & Araç Kirası & 4 & & & & & & & 250 & 250 \\
\hline & Fotogrametrik Nokta Tesis & 2 & 1 & 250 & & & & 30 & 20 & 850 \\
\hline & Fotogrametrik Nokta Ölçüm & 2 & 1 & & & & & & & \\
\hline 4 & $\begin{array}{l}\text { FotoğrafÇekimi } \\
\text { (725 Adet / 0.05) }\end{array}$ & & & & & & & 36.25 & 0.05 & 36.25 \\
\hline 5 & Dengeleme & 3 & 1 & 250 & & 40.14 & & & & 290.14 \\
\hline 6 & Kıymetlendirme Hizmeti & 24 & 1 & 750 & & 321.12 & & & & 1071.12 \\
\hline \multirow[t]{2}{*}{7} & Bütünleme Hizmeti & 48 & 1 & 1500 & & 642.24 & & & & 2142.24 \\
\hline & & & & & & & & & Toplam $=$ & 8643.29 \\
\hline
\end{tabular}


İncelenen diğer sistem döner kanatı İHA sistemidir. Döner kanatlı İHA sisteminin maliyeti $13000 \mathrm{TL}$ dir. Sabit kanatlı İHA sisteminde olduğu gibi İHA nın bir üst modeli yaklaşık üç yıl sonra çıktı̆̆ hesap edilmiştir. Bu üç yıl içerisinde yaklaşık yüz uçuş yapılacağı hesap edilerek yüz uçuş sonucunda amortisman gideri satın alma maliyetidir. IHHA' nın bu projedeki bir saatlik uçuş maliyetini ise $=$ [Satın alma maliyeti/(100x17)] dir. Buradaki 17 rakamı ise kampüs alanında saat biriminde uçuş süresidir. Bu formüle göre İHA' nın bir saatlik uçuş maliyeti=[13.000/(100x17)]= 7.65 TL dir. Pilot bölgenin fotogrametrik olarak alımının yapılması için uçuş planlaması yapılmıştır. Bu planlama bir saat sürmüş planlama sonucunda uçulacak kolon sayısı, uçuş yüksekliği ve fotoğrafların enine ve boyuna bindirme oranları hesap edilmiştir. Sabit kanatlı İHA da kullanılan YKN bu çalışmada da ortak kullanılmıştır. Bir adet YKN maliyeti 20 TL dir. Bölgenin fotoğraflanması çalışması 800 adet fotoğraf çekimi ile tamamlanmıştır. Bu fotoğraflar altı adet lipo pili şarj edip otuz adet uçuş yapılarak elde edilmiştir. Bir pilin satın alma maliyeti $2100 \mathrm{TL}$ dir. Bir fotoğrafın çekim maliyeti ise: $[((2100 \times 6) / 100) / 800]=$ 0.16 TL dir.

Yazılımın yaklaşık fiyatı $4045 \times 7,94=32117 \mathrm{TL}$ dir. Yazılımın üst versiyonu ortalama üç yılda çıktı̆̆ öngörülerek amortismanı hesap edilmiştir. Dolayısıyla bu üç yıl süre içerisinde yüz uçuşluk değerlendirme işlemi yapılacağı hesap edilerek yazılımın bir saatlik değerlendirme maliyeti; [32117/(100x24)]= $13.38 \mathrm{TL}$ dir. Bu hesaplamaların sonucunda döner kanatlı İHA fotogrametrisinin yaklaşık maliyet hesabı Tablo 6'da bulunmuştur. 


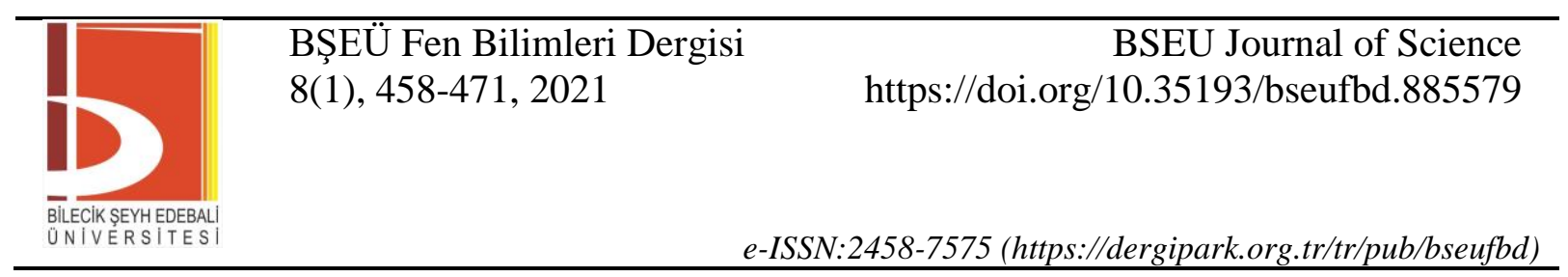

Tablo 6. Döner kanatlı hava fotogrametrisi yaklaşık maliyet hesabı

\begin{tabular}{|c|c|c|c|c|c|c|c|c|c|c|}
\hline & İşlem & $\begin{array}{l}\text { Süre } \\
\text { (Saat) }\end{array}$ & $\begin{array}{l}\text { Personel } \\
\text { Sayisi }\end{array}$ & $\begin{array}{c}\text { Personel } \\
\text { Ücreti } \\
\text { (250 Tl/Gün) }\end{array}$ & $\begin{array}{c}\text { Uçuş } \\
\text { Ücreti } \\
\text { (T1/Saat) }\end{array}$ & $\begin{array}{l}\text { Yazilim } \\
\text { Ücreti } \\
\text { (TI/Saat) }\end{array}$ & $\begin{array}{c}\text { Donanim } \\
\text { Ücreti } \\
\text { (Tl/Saat) }\end{array}$ & $\begin{array}{c}\text { Hizmet } \\
\text { Miktari } \\
\text { (Adet) }\end{array}$ & $\begin{array}{l}\text { Hizmet } \\
\text { Ücreti } \\
\text { (T1/Adet) }\end{array}$ & $\Sigma(\mathrm{Tl})$ \\
\hline \multirow{3}{*}{1} & Uçuş Hizmet Bedeli & & & & & & & & & \\
\hline & İntikal & & & & & & & & & \\
\hline & Uçuş & 17 & 1 & 750 & 130.05 & & & & & 880.05 \\
\hline \multirow{4}{*}{2} & Uçuş öncesi ve sonrası gerçekleştirilen hizmetler & & & & & & & & & \\
\hline & & & & & & & & & & \\
\hline & Uçuş planlaması & 1 & 1 & & & & & & & \\
\hline & $\begin{array}{l}\text { Yer control noktası inşaası ve ölçüm hizmeti (Arazi) } \\
\text { (Gnss Cihazı) }\end{array}$ & 2 & & & & & 133.33 & & & 266.66 \\
\hline \multirow[t]{3}{*}{3} & Araç kirası & 17 & & & & & & & 750 & 750 \\
\hline & Fotogrametrik Nokta tesis & 2 & 1 & 250 & & & & 30 & 20 & 850 \\
\hline & Fotogrametrik Nokta ölçüm & 2 & 1 & & & & & & & \\
\hline 4 & $\begin{array}{l}\text { Fotoğraf çekimi } \\
(800 \text { Adet })\end{array}$ & & & & & & & 800 & 0.16 & 128 \\
\hline 5 & Dengeleme & 3 & 1 & 250 & & 40.14 & & & & 133.89 \\
\hline 6 & Kyymetlendirme hizmeti & 24 & 1 & 750 & & 321.12 & & & & 1071.12 \\
\hline \multirow[t]{2}{*}{7} & Bütünleme hizmeti & 48 & 1 & 1500 & & 642.24 & & & & 1071.12 \\
\hline & & & & & & & & & Toplam= & 6221.90 \\
\hline
\end{tabular}




\section{B. Yersel Ölçüm Tekniği Maliyet Analizi}

Çalışma alanının yersel ölçüm teknikleri ile yapılması durumunda maliyetin araştııılması için iki farklı kaynaktan faydalanılmıştır. Bunlar; İller bankası ve Harita Kadastro Mühendisleri odası (HKMO)'nın belirlemiş olduğu yıllara göre değişiklik gösteren birim fiyatları tablosudur.

İlk analiz İLBANK A.Ş.' nin resmi internet sitesinde yer alan İller Bankası A.Ş. Yatırım Koordinasyon Dairesi Başkanlığı 2020 Yılı Sayısal Hâlihazır Harita Alım İşleri Birim Fiyat Cetveli esas alınarak hazırlanmıştır (Sayısal Hâlihazır Harita Alım İşleri Birim Fiyat Cetveli, 2020). Çalışma alanı toplam 512 ha dır. Bu çalışma alanının 400 ha gayrimeskûn saha, 112 ha ise meskûn saha olarak dikkate alınarak hesaplamalar yapılmıştır. Bu maliyet analizinde $\% 20$ yüklenici karı ve $\% 18 \mathrm{KDV}$ oranları göz önünde bulundurulmuştur.

Tablo 7. ILBANK A.Ş. 2020 Yılı Sayısal Hâlihazır Harita Alım İşleri Birim Fiyat Cetveline göre hazırlanmış çalışma alanına ait yersel ölçüm tekniği ile hâlihazır harita yapımı maliyet analizi

\begin{tabular}{|c|c|c|c|c|c|}
\hline \multicolumn{6}{|c|}{ İLBANK A.Ş. 2020 Yılı Sayısal Hâli hazır Harita Alım İşleri Birim Fiyat Cetveli } \\
\hline & İş̧ & Birim & Birim Fiyat & Çarpan & Fiyat (Tl) \\
\hline Gayrimeskûn & $\begin{array}{c}\text { 1/1000 Ölçekli hâli hazır } \\
\text { harita yapım işi }\end{array}$ & Hektar & 685.24 & 400 & 274096 \\
\hline \multirow[t]{2}{*}{ Meskûn } & $\begin{array}{c}\text { 1/1000 Ölçekli hâli hazır } \\
\text { harita yapım işi }\end{array}$ & Hektar & 1114.73 & 112 & 124849.80 \\
\hline & & & & Toplam $=$ & 398945.80 \\
\hline
\end{tabular}

HKMO Mühendislik Hizmetleri Ücret Cetveli 2020/2; ücretler cetvelinde yaklaşık 10x10 m aralıklı plankote yapımı için 0-500 $\mathrm{m}^{2}$ alan için $1760 \mathrm{TL}$ fiyat belirlenmiştir. Çalışma alanı $500 \mathrm{~m}^{2}$ den büyük ise; 500 $10.000 \mathrm{~m}^{2}$ ' ye kadar her $500 \mathrm{~m}^{2}$ için $310,00 \mathrm{TL}$ eklenir. $10.000 \mathrm{~m}^{2}$ ' den büyük alanlarda her ha için $1.540,00 \mathrm{TL}$ eklenir denilmektedir. Bu veriler dikkate alarak çalışma alanımızdaki maliyet hesap edilmiş ve Tablo 8 de gösterilmiştir. Hesaplamalar yapılırken yöresel katsayı 1 olarak kabul edilmiştir. Tüm tekniklerin maliyet analiz grafiği şekil 7 de görülmektedir.

Tablo 8. HKMO Mühendislik Hizmetleri Ücret Cetveli 2020/2; çalışma alanına ait yersel ölçüm tekniği ile yaklaşık 10x10 m aralıklı Plankote yapımı maliyet analizi

\begin{tabular}{cccc}
\hline \multicolumn{3}{c}{$\begin{array}{c}\text { HKMO Mühendislik Hizmetleri Ücret Cetveli 2020/2; } \\
\text { Yaklaşı 10x10 m aralıklı Plankote yapımı }\end{array}$} \\
\hline ALAN & $0-500 \mathrm{~m}^{2}$ & $500-10000 \mathrm{~m}^{2}(\mathrm{TL})$ & $10000 \mathrm{~m}^{2}$ büyük her hektar için (TL) \\
512 & 1760 & 155 & 845 \\
& 2945 & 431795 \\
\hline & & Toplam $=$ & 436500 \\
\hline
\end{tabular}




\begin{tabular}{|c|c|c|}
\hline & $\begin{array}{l}\text { BŞEÜ Fen Bilimleri Dergisi } \\
8(1), 458-471,2021\end{array}$ & $\begin{array}{r}\text { BSEU Journal of Science } \\
\text { https://doi.org/10.35193/bseufbd.885579 }\end{array}$ \\
\hline $\begin{array}{l}\text { BïLECIK SEYH EDEBALI| } \\
\text { UNIVERSITES I }\end{array}$ & & 2458-7575 (https://dergipark.org.tr/tr/pub/bseufbd) \\
\hline
\end{tabular}

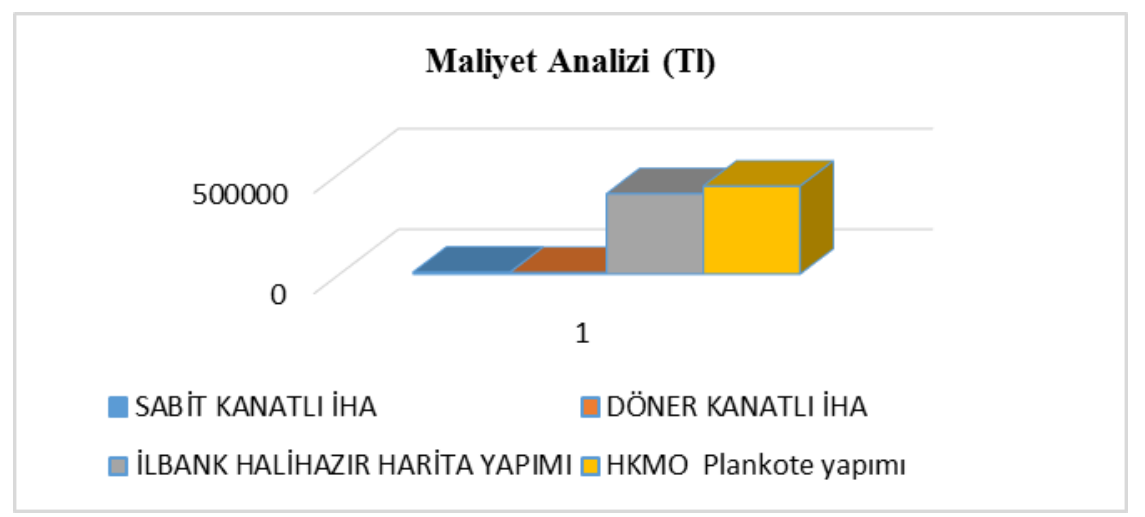

Şekil 7. Kullanılan tekniklerin maliyet analizi grafiği

\section{SONUÇLAR}

Büyük ölçekli harita ve harita bilgileri üretim yönetmeliği de Detay ölçme doğruluğu (Madde 46- (1) Detay noktalarının izdüşüm koordinatları ve yükseklikleri, elektronik takeometre, GNSS, LIDAR veya diğer teknik ve yöntemler kullanılarak; yatay konum doğruluğu $\sqrt{\left(\sigma x^{2}+\sigma y^{2}\right)} \pm 7 \mathrm{~cm}$ (dâhil)'den daha iyi ve Helmertortometrik yükseklik doğruluğu $(\sigma \mathrm{H}) \pm 7 \mathrm{~cm}$ (dâhil)'den daha iyi olacak şekilde ölçülmelidir.) denmektedir. İHA ile üretilen ortofoto haritalardaki konumsal doğruluklar incelendiğinde $\pm 7 \mathrm{~cm}$ biraz üstünde olduğu görülmektedir. Bu durumun önüne geçilebilmesi için uçuş için belirlenen Yer örnekleme aralığı değeri düşürülmelidir.

Analizler sonucunda, İHA fotogrametrisi ile harita üretilmesinde sabit kanatlı İHA ile üretilen harita, döner kanatlı İHA ile üretilen harita maliyetine göre \% 38.91 oranında daha yüksek maliyet oranı çıkmıştır. Yersel yöntemler ise; İLBANK A.Ş. 2020 Yılı Sayısal Hâlihazır Harita yapımı 398945.8 TL lik maliyeti ile döner kanatlı İHA sistemine göre 64.12 kat daha maliyetlidir. 10x10 m aralıklı Plankote yapımı ise 436500 TL lik maliyeti ile döner kanatlı İHA sistemine göre 70.16 kat daha maliyetlidir.

Çalışma kapsamındaki uygulamanın sonuçlarından da anlaşılacağı üzere insansız hava araçları ile fotogrametrik ölçme ve değerlendirme işlemi gelişen teknoloji ile beraber mühendislik projelerinde kullanılır hale gelmiştir. Gerek zaman ve maliyet tasarrufu açısından, gerekse doğruluk ve görsellik açısından İHA fotogrametrisinin mühendislik projelerinde etkin olarak kullanılabileceği görülmektedir.

\section{KAYNAKLAR}

[1] Ahmad, A. \& Chandler, J. H. (1999). Photogrammetric Capabilities of the Kodak DC40, DCS420 and DCS460 Digital Cameras, Photogrammetric Record, 16 (94), 601-615.

[2] Habib, A., Shan, J. \& Toth, C. K. (2009). Accuracy, quality assurance, and quality control of LiDAR data. Topographic Laser Ranging and Scanning: Principles and Processing, 269-94.

[3] Salleh, M. R. M., Ismail, Z. \& Rahman, M. Z. A. (2015). Accuracy assessment of lidar-derived digital terrain model (DTM) with different slope and canopy cover in tropical forest region. ISPRS Annals of the Photogrammetry, Remote Sensing and Spatial Information Sciences, 2(2), 183.

[4] Torge, W. \& Müller, J. (2012). Geodesy, 3rd ed;Walter de Gruyter: New York, NY, USA

[5] Erol, S. \& Erol, B. (2021). A comparative assessment of different interpolation algorithms for prediction of GNSS/levelling geoid surface using scattered control data. Measurement, 173, 108623.

[6] Wang, Y. M., Becker, C., Mader, G., Martin, D., Li, X., Jiang, T., ... \& Bürki, B. (2017). The Geoid Slope Validation Survey 2014 and GRAV-D airborne gravity enhanced geoid comparison results in Iowa. Journal of Geodesy, 91(10), 1261-1276.

[7] Kayı, A., Erdoğan, M. \& Eker, O. (2015). LiDAR test results carried out using OPTECH HA-500 and RIEGL LMS-Q1560. Map J. 153, 42-46.

[8] Yilmaz, N. \& Cakir, L. (2016). A research of consistencies and progresses of geoid models in Turkey. Arabian Journal of Geosciences, 9(1), 1-11.

[9] Wever, C. \& Lindenberger, J. (1999). Experiences of 10 years laser scanning. In: Photogrammetric Week 99. 


\section{BŞEÜ Fen Bilimleri Dergisi}

$8(1), 458-471,2021$

BSEU Journal of Science

https://doi.org/10.35193/bseufbd.885579

[10] Sties, M., Kruger, S., Mercer, J. B. \& Schnick, S. (2000). Comparison of digital elevation data from airborne laser and interferometric SAR systems. International Archives of Photogrammetry and Remote Sensing, 33(B3/2; PART 3), 866-873.

[11] Lichti, D. \& Skaloud, J. (2010). Registration and calibration. In Air borne and Terrestrial Laser Scanning; Vosselman, G., Maas, H.G., Eds.; Whittles Publishing, 336.

[12] Ravi, R. \& Habib, A. (2020). Fully Automated profile-based calibration strategy for airborne and terrestrial mobile LiDAR systems with spinning multi-beam laser units. Remote Sensing, 12(3), 401.

[13] Beraldin, J.A., Blais, F., \& Lohr, U. 2010. Laser scanning technology. In Air borne and Terrestrial Laser Scanning; Vosselman, G., Maas, H.G., Eds. Whittles Publishing: Scotland, UK, 2010; 336.

[14] Zhang, W. \& Li, Q. (2006). A preliminary simulation to study the potential of integration of LIDAR and imagery. In Remote Sensing for Environmental Monitoring, GIS Applications, and Geology VI (Vol. 6366, p. 63660W). International Society for Optics and Photonics.

[15] Süleymanoğlu, B. \& Soycan, M. (2019). Comparison of filtering algorithms used For DTM Production from airborne LiDAR data: A case study in Bergama, Turkey.

[16] Fonstad, M. A., Dietrich, J. T., Courville, B. C., Jensen, J. L. \& Carbonneau, P. E. (2013). Topographic structure from motion: a new development in photogrammetric measurement. Earth surface processes and Landforms, 38(4), 421-430.

[17] Agüera-Vega, F., Carvajal-Ramírez, F. \& Martínez-Carricondo, P. (2017). Assessment of photogrammetric mapping accuracy based on variation ground control points number using unmanned aerial vehicle. Measurement, 98, 221-227.

[18] Tahar, K. N. (2013). An Evaluation On Different Number of Ground Control Points in Unmanned Aerial Vehicle. Photogrammetric Block XL. 27-29. 